\title{
Evolution and Differentiation of High-Quality Development of Marine Economy: A Case Study from China
}

\author{
Bo Li, ${ }^{1}$ Chuang Tian $\left(\mathbb{D},{ }^{2}\right.$ Zhaoyuan Shi $\mathbb{D}^{3},{ }^{3}$ and Zenglin Han ${ }^{1}{ }^{1}$ \\ ${ }^{1}$ Center for Studies of Marine Economy and Sustainable Development, Liaoning Normal University, Dalian 116029, China \\ ${ }^{2}$ School of Maritime Economics and Management, Dalian Maritime University, Dalian 116026, China \\ ${ }^{3}$ School of Geography and Planning, Sun Yat-Sen University, Guangzhou 510275, China \\ Correspondence should be addressed to Chuang Tian; tcyeah@dlmu.edu.cn and Zenglin Han; hzl@lnnu.edu.cn
}

Received 21 April 2020; Accepted 29 May 2020; Published 11 July 2020

Guest Editor: Jianhong (Cecilia) Xia

Copyright (c) 2020 Bo Li et al. This is an open access article distributed under the Creative Commons Attribution License, which permits unrestricted use, distribution, and reproduction in any medium, provided the original work is properly cited.

\begin{abstract}
High-quality development is an innovative way to promote the sustainable development of the marine economy. This study uses China's coastal areas as an example, constructing a research framework for the high-quality development of the country's marine economy. The temporal and spatial variation in the high-quality development of China's marine economy from 2006 to 2016 is explored utilizing the nuclear density estimation, entropy, and mean standard deviation classification methods. The results show the following: (1) the policy orientation of China's high-quality marine economic development is obvious, and the focus of policy has changed from the pursuit of growth speed to growth quality; (2) a spatiotemporal differentiation is evident, with the coastal areas of the Yangtze River Delta continuing to be the hotspots of high-quality development. The Bohai rim and Pan Pearl River Delta areas feature a mixture of cold and hot spots, with multipolar spatial differentiation; (3) in terms of development stage, Guangdong, Shanghai, Shandong, Zhejiang, and Tianjin are at advanced levels. The intermediate-level areas consist of Fujian, Jiangsu, Hainan, and Liaoning, while Hebei and Guangxi are the primary-level areas.
\end{abstract}

\section{Introduction}

By the end of the 20th century, many Nobel Prize winners had reached a consensus on the top ten problems facing humanity in the next half century: energy, water, food, environment, poverty, terrorism and war, disease, education, democracy, and population [1]. In fact, countries around the world have started to focus on oceans' sustainability because of survival risks and potential resource scarcity. As a key to implementing national marine strategies, coastal cities play a significant role in land-sea interactions and marine-related human activities. These cities are facing multiple threats from high-density agglomeration, high-intensity development, and high levels of pollution and ecological risks [2, 3]. It has been widely recognized by coastal cities that socioecological models must be explored to improve the sustainable development $[4,5]$.

The 21 st century has witnessed the comprehensive exploration and utilization of oceanic resources. Given the concept of sustainability and the development of marine economy, examining how to shift the marine economy away from an extensive type has become a topic of research among scholars and governments. The common objective now for coastal countries is to achieve sustainable growth of the marine economy by solving historical environmental issues such as "inadaptability" and "incompatibility" [6-8].

Many of the existing studies on the growth of the marine economy qualitative analysis as the main line and quantitative analysis as the research framework [9] mainly cause analysis of the aggregate economy [10] and comparative studies [11]. The research focus of the previous literature tends to switch between the macroscale and the microscale. In fact, research continues to be refined at each scale and among internal units and is beginning to focus more attention on the operations of marine economies at the microeconomic level [12]. Based on the changes in the external environment of the marine economy as well as the dynamic evolution of internal structures, the comprehensive study of 
typical regions and specific case analysis have become key research areas. Furthermore, popular research topics include diagnostic analysis of the threats to the interactive relationship [13, 14], risk assessment of the pathological pursuit of economic growth [15, 16], coupled and coordinated development [17, 18], threshold and carrying capacity [19], and accounting for resource depletion [20, 21]. Related research focuses on how to achieve sustainable development of the marine economy, though the emphasis has shifted from understanding the rate at which the marine economy is growing to the quality of sustainable marine economic growth [22].

In China, $43 \%$ of the country's population live in coastal areas, forming more than $55 \%$ of the gross national product (GNP). Coastal areas have absorbed approximately $80 \%$ of direct investment and received more than $90 \%$ of the total import and export trade, allowing it to become a powerful engine for the development of the national economy. Thus, the development of coastal cities has an influence on the running situation of the entire country. China's focus on the transformation of the marine economy is shifting from highspeed growth to high-quality development, given the increasing pressure to preserve resources and the environment in coastal areas, in order to be innovative in realizing the sustainable development of the marine economy [23].

Existing literature on the growth of the marine economy focuses more on the magnitude of growth, with little research being conducted on the quality of growth. Traditional marine economic growth emphasizes the speed of growth, while high-quality development emphasizes the advantages and disadvantages of growth. The negative effects of the external environment, such as shrinking demand and diminishing demographic dividend, have forced the development of the marine economy, under the constraint of a structural slowdown crisis, to shift to the long-term perspective in terms of speed, structure, and power changes in time and space, so as to achieve sustainable growth and improve human welfare [24]. It aims to optimize the structure of marine industries, promote marine social welfare, and enhance the marine ecological environment based on the improvement of the comprehensive strength of the marine economy $[8,22,25]$. In particular, the human-ocean system and its subsystems are the main areas where high-quality development can improve the marine economy, while carriers that support the development of the marine economy are areas that can improve marine economic activity at all levels. Relevant carriers achieve the coordination and healthy development of the systems via the exchange of substance and information on the human-ocean system [24].

This study uses China's coastal areas as an example, constructing a research framework for the high-quality development of the country's marine economy. The temporal and spatial variation of the high-quality development of China's marine economy from 2006 to 2016 is explored by utilizing the nuclear density estimation, entropy, and mean standard deviation classification methods. We identify the development stages and specific research sample types, in order to contribute to the sustainable development of the national marine economy.
The high-quality development of China's marine economy mainly relies on guidance from the national macroeconomic marine policy and the supplementary promotion of local targeted maritime laws and regulations. The release of coastal policies has changed over time from a brief and scattered pattern to a systematic and intensive pattern, while the focus of the policies has shifted from the growth rate to the quality of marine economic development (Figure 1).

\section{Method}

2.1. Variable Selection and Processing. Based on the analysis of the features that define the quality of marine economic development (Figure 2), an index system for the high-quality development of the marine economy was constructed, as shown in Table 1. The variable for maritime comprehensive strength reflects the material basis for the high-quality development of the marine economy and mainly includes the scale and indicators of the economic expansion of the marine economy. The structure of marine industries is an indicator for the proportion and output of three sectors of the maritime economy and reflects their level of structural optimization as well as the internal structure and growth pattern of marine economic development. Marine social welfare is reflected in the indicator for the benefits brought to the public through the high-quality development of the marine economy, such as employment, livelihood, science and technology, and income; these also reflect the goals of marine economic development. Marine ecological environment represents the indicator for the protection and destruction of the marine environment, which mainly reflects the price paid for achieving the high-quality development of the marine economy. Due to the limitation of the marine data, the areas studied in this paper include 8 coastal provinces, 1 autonomous region, and 2 municipalities (excluding Hong Kong, Macao, and Taiwan) in China.

Specifically, the calculations are as follows:

(i) Marine resources are a weighted sum of marine spatial resources (e.g., sea area, coastline, and seabed), marine biological resources (e.g., volume of marine aquaculture and amount of marine fishing), marine chemical resources (e.g., sea salt), marine mineral resources (oil and natural gas), and marine tourism resources (e.g., star hotels in coastal areas)

(ii) Index of market organizations in coastal area$s=$ total industrial output of coastal areas/total number of coastal industries

(iii) Fiscal self-financing rate in coastal areas = revenue within general budgets of local governments in coastal areas/expenditure within general budgets of local governments

(iv) The level of support by national policies is rated as " 3 ," " 2 ," or " 1 " according to the frequency of occurrences of the area's name and the number of supporting policies in national marine policies and regulations 


\begin{tabular}{|c|c|c|c|c|}
\hline $1949 \sim 1978$ & $1979 \sim 1990$ & $1991 \sim 2000$ & $2001 \sim 2010$ & 2011 Now \\
\hline $\begin{array}{l}\text { (i) Extensive } \\
\text { development } \\
\text { period }\end{array}$ & $\begin{array}{l}\text { (i) The initial stage } \\
\text { of reform and } \\
\text { opening up: the } \\
\text { growth of marine } \\
\text { economy is the } \\
\text { main part, } \\
\text { supplemented by } \\
\text { the development } \\
\text { and protection }\end{array}$ & $\begin{array}{l}\text { (i) Establishing the } \\
\text { concept of } \\
\text { sustainable } \\
\text { development in } \\
\text { the field of } \\
\text { marine economy }\end{array}$ & $\begin{array}{l}\text { (i) Deepen the } \\
\text { development of } \\
\text { both quantity and } \\
\text { quality and } \\
\text { promote the } \\
\text { common } \\
\text { development of } \\
\text { marine economy } \\
\text { and ecology }\end{array}$ & $\begin{array}{l}\text { (i) 'New normal of } \\
\text { economy' } \\
\text { (ii) Marine economy } \\
\text { develops to high } \\
\text { quality on the } \\
\text { basis of land and } \\
\text { sea coordination }\end{array}$ \\
\hline
\end{tabular}

FIgURE 1: China’s marine policy stage.

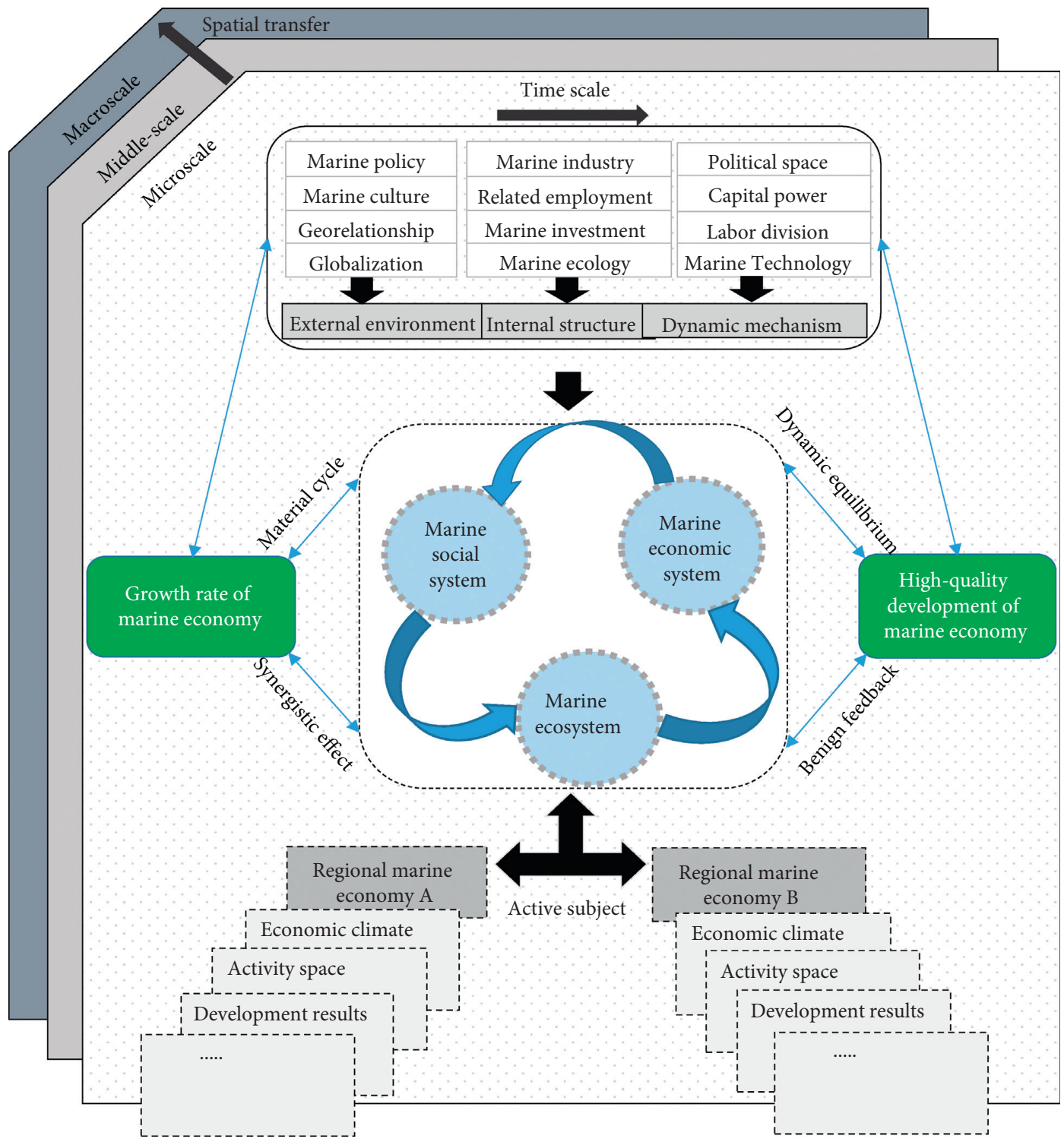

FIGURE 2: The features of the high-quality development of marine economy.

(v) Fluctuations of marine economic growth = (growth rate of marine economy in the same year-growth rate of marine economy in the previous year)/ growth rate of marine economy in the previous year (vi) Index of upgrading of marine industries = output of marine tertiary industry/output of marine secondary industry;

(vii) Location quotient of marine industries $=$ (output of marine industries in the region/gross output of 


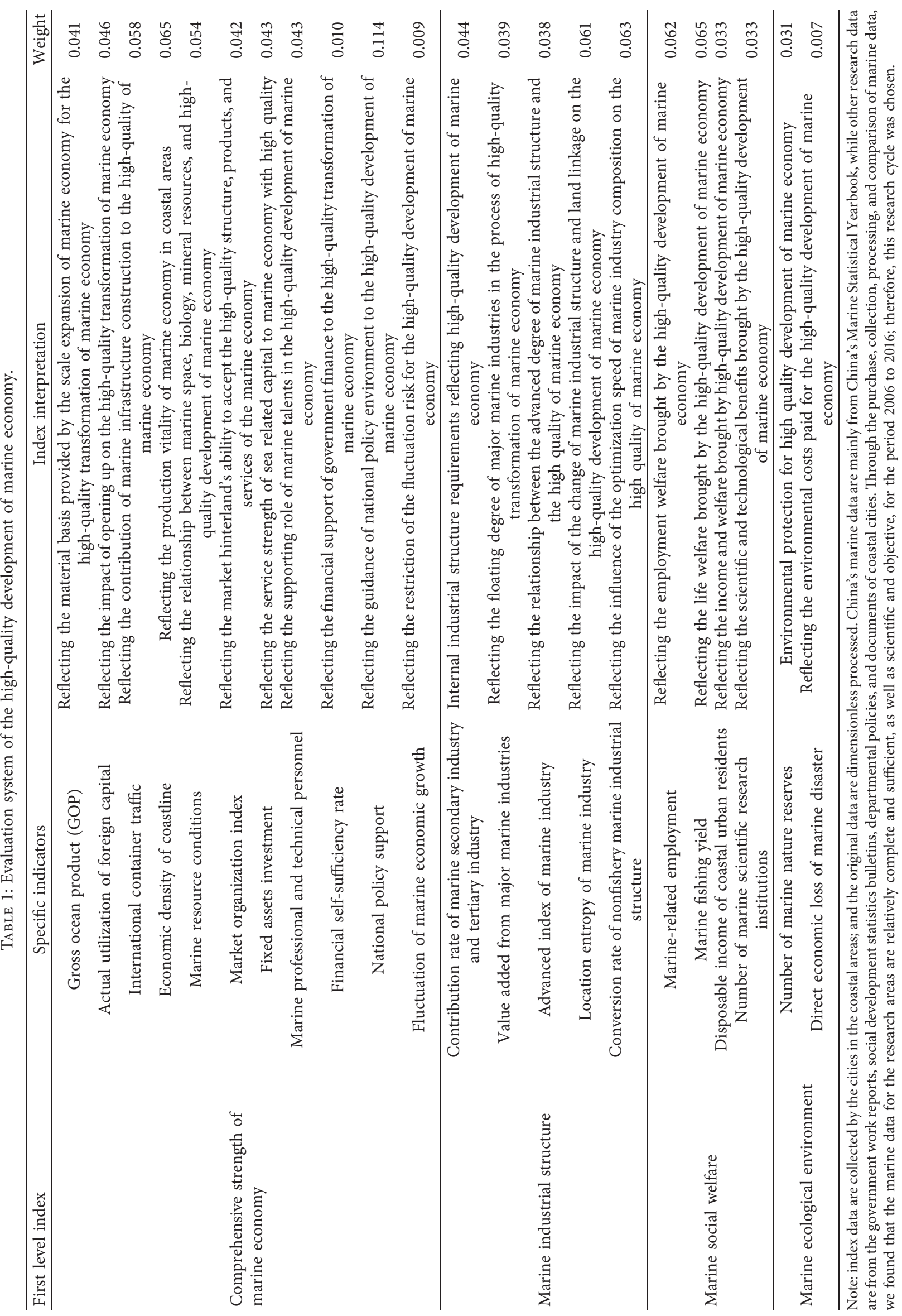


all industries in the region)/(output of marine industries in the country/gross output of all industries in the country);

(viii) Ratio of structural changes in marine industries (except fisheries) $=\sqrt{\sum_{i=1}^{n}\left(\left(N_{i}-G\right)^{2} \times K_{i}\right) / G}$,

where $N_{i}$ is the output of marine industries (except fisheries), $G$ refers to the average annual growth rate of gross ocean product, and $K$ represents the proportion of the output of marine industries (except fisheries) in the gross ocean product.

2.2. Entropy Method. The entropy method is a mathematical method used to judge the dispersion degree of an index. The greater the degree of dispersion, the greater the impact of this index is on the comprehensive evaluation. It is an objective weighting method adopted to determine the weight of the relevant indicators in order to improve the accuracy and validity of the score for the high-quality development of the marine economy [26, 27]. By standardizing the original data [28] and then calculating the weight of relevant indicators (which can be used to evaluate the high-quality development of the marine economy in spatial samples), we can then calculate the total score for China.

2.3. Kernel Density Estimation. Kernel density estimation $(\mathrm{KDE})$ is used to estimate the probability density function of a random variable in the probability theory, which can reveal the evolution of the high-quality development of the marine economy in a temporal dimension [22, 29]. Time series analysis of the waveform, position, and kurtosis of a $\mathrm{KDE}$ curve can reveal the pattern of dynamic changes of the high-quality development of the marine economy on the time scale. For data $x_{1}, x_{2}, x_{3}, \ldots, x_{n}$, its KDE can be expressed as

$$
\hat{f_{h}} \hat{(x)}=\frac{1}{n h} \sum_{i=1}^{n} K\left(\frac{x-x_{i}}{h}\right),
$$

where the kernel function $K$ is a weight function, $h$ refers to the bandwidth, and $x-x_{i}$ represents the distance between $x$ and $x_{i}$. Commonly used kernel functions include uniform, triangle, gamma, and Gaussian kernel functions. According to the density of the selected data, Gaussian kernel function was adopted for this study:

$$
\text { Gaussian }=\frac{1}{\sqrt{2 \pi}} e^{-(1 / 2) t^{2}} .
$$

The bandwidth $h$ was selected as $h=0.9 \mathrm{SN}-0.8$ based on Silverman's rules, and $S$ was the standard deviation of the observed value of the random variable [30].

\section{Results}

3.1. Characteristics of Temporal Evolution. The entropy method was used to calculate the score for the high-quality development of the marine economy, and the temporal variation of the development was investigated using the $\mathrm{KDE}$ (Figure 3(a)). In terms of the shape of the kernel, the KDE waveform showed a multimodal distribution. The kernel density distribution corresponding to the peak of the curve in 2006 was scattered; the difference in scores between regions was relatively small. The kernel density distribution corresponding to the peak of the curve in 2016 was relatively concentrated, and the gap in the quality of marine economics between regions widened. From 2006 to 2016, the peaks of the kernel density curve all shifted to the right with higher fluctuations of the score; the high-quality development of the marine economy steadily improved, indicating "club convergence."

In order to explore the time evolution of the high-quality development of the marine economy in China over a longer period of time, the development was divided into three stages-primary, fluctuation, and stable stages, with 0.04 (standard deviation set) as the cutoff point. The quantitative division of the stages of development against scores is more objective than qualitative division. From 2006 to 2009, the development of China's marine economy was in the primary stage, that is, it was of relatively low quality. From 2010 to 2014, the development of China's marine economy was in the fluctuation stage and was of medium quality. Between 2015 and 2016, the development of China's marine economy entered a stable stage of high quality (Figure 3(b)). China's marine economic growth has significantly decreased-the marine economy has changed from a high-speed growth stage to a high-quality development stage, with such a transformation being urgently required (Figures $3(\mathrm{c})$ and $3(\mathrm{~d})$ ).

3.2. Characteristics of Spatial Evolution. Natural break classification was adopted to divide the primary, intermediate, and advanced stages of the high-quality development to explore the spatial evolution of the marine economy. From 2006 to 2016, the coastal areas of the Yangtze River Delta (YRD) continued to be the hot spots, in general. The coastal areas of the Pearl River Delta (PRD) and the Bohai Economic Rim (BER) showed a mix of hot and cold spots. The spatial evolution of the high-quality development of the marine economy was basically established based on this data.

In 2006, Guangdong, Shanghai, Zhejiang, and Shandong Provinces were in the advanced stage of high-quality development; Tianjin, Jiangsu, Fujian, and Hainan Provinces were in the intermediate stage; and Guangxi, Hebei, and Liaoning Provinces were in the primary stage. In 2010, Guangdong, Shanghai, and Shandong Provinces were in the advanced stage; Tianjin, Jiangsu, Zhejiang, Fujian, and Hainan Provinces were in the intermediate stage; and Guangxi, Hebei, and Liaoning Provinces were in the primary stage. In 2014, Guangdong, Shanghai, Zhejiang, Tianjin, and Shandong Provinces were in the advanced stage; Jiangsu, Fujian, Hainan, and Liaoning Provinces were in the intermediate stage; Guangxi and Hebei Provinces were in the primary stage. By 2016, the high-quality development of China's marine economy 


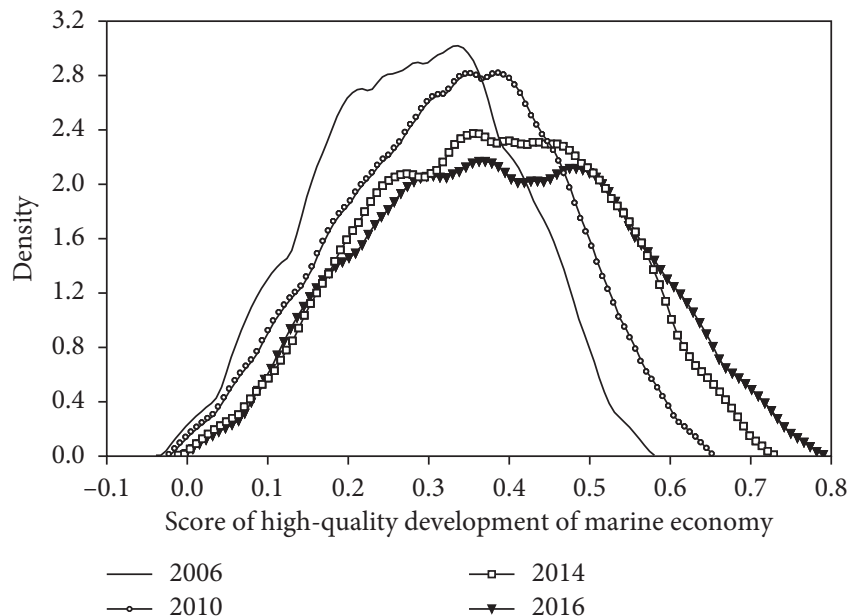

(a)

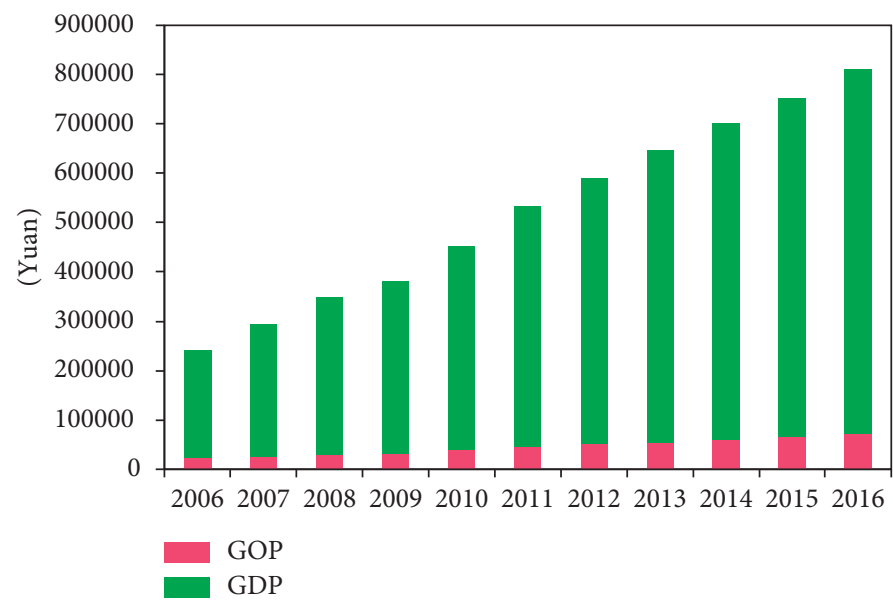

(c)

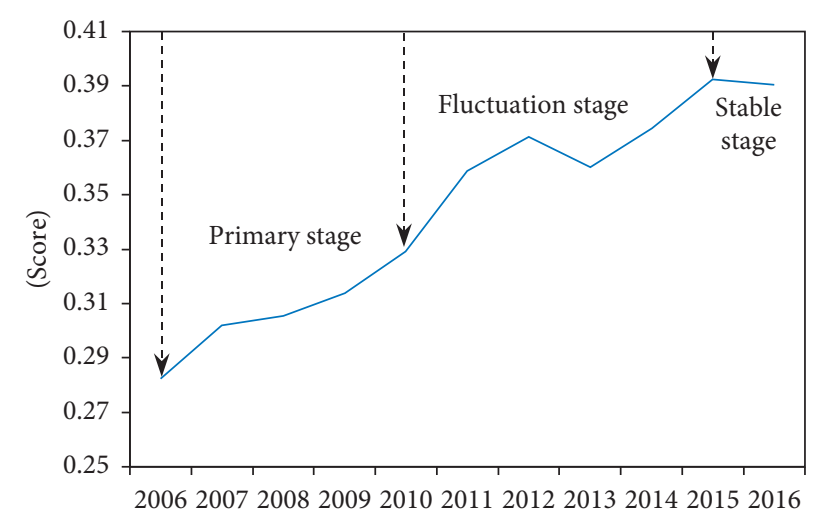

(b)

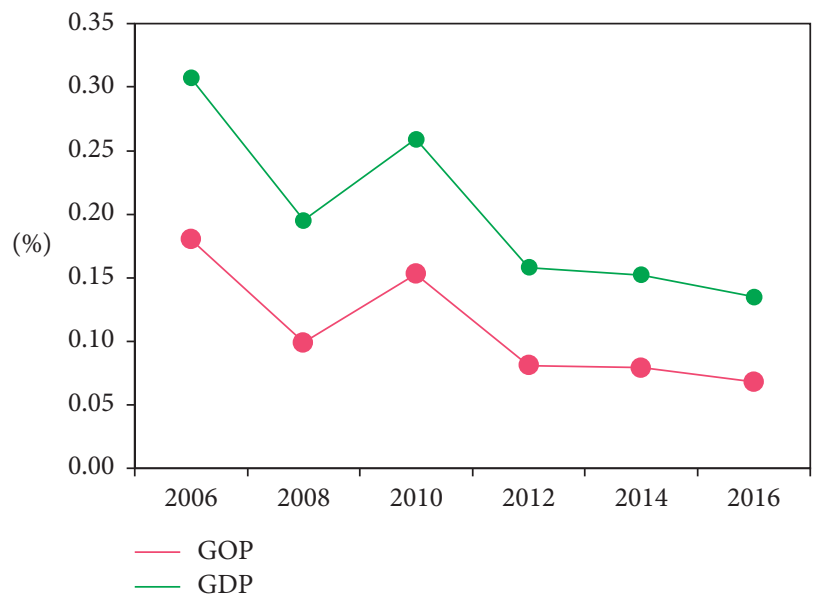

(d)

Figure 3: Time evolution and stage division of the high-quality development of marine economy. (a) Nuclear density distribution. (b) Time stage. (c) GOP and GDP output. (d) Growth rate of GOP and GDP.

became multipolar, alternating between high, medium, and low qualities, showing a multipeak distribution (Figure 4).

3.3. Type Identification. Coastal areas in China were categorized into three types based on their scores for highquality development of the marine economy using the mean-standard deviation classification [31]. The meanstandard deviation classification is mainly based on the deviation of the data itself, which fits the actual situation better than the other classification methods types. $M>A$ suggests an advanced-level area; $A-\mathrm{SD}<M<A$ refers to an intermediate-level area; and $M<A-\mathrm{SD}$ indicates a primarylevel area, where $M$ is the score for the high-quality development of the sample marine economy, $A$ is the average annual score, and SD is the standard deviation. From 2006 to 2016, the average score $(A)$ for the high-quality development of China's marine economy $(M)$ was 0.35 , and the standard deviation (SD) was 0.13. Therefore, the score range for advanced-level areas was $0.35-1.00$; the score range for intermediate-level areas was $0.22-0.35$; and the score range for primary-level areas was $0.00-0.22$.

3.4. Advanced-Level Areas. Tier I areas are advanced-level areas, which include Guangdong, Shanghai, Shandong, Zhejiang, and Tianjin. The following describes each area in relation to sustainable growth in the marine economy:

(1) Guangdong Province benefits from a large number of land-based economies, and its marine economy is strongly driven by economic hinterland, market absorption, offshore finance, and high technologies. The rapid expansion of Guangdong's marine economy forms a solid foundation for the transformation of the marine economy from high-speed to highquality development.

(2) Shanghai is the core area in the YRD region. It exhibits unique advantages for the development of the marine economy, given its importance in national strategies, identity as an international city, 


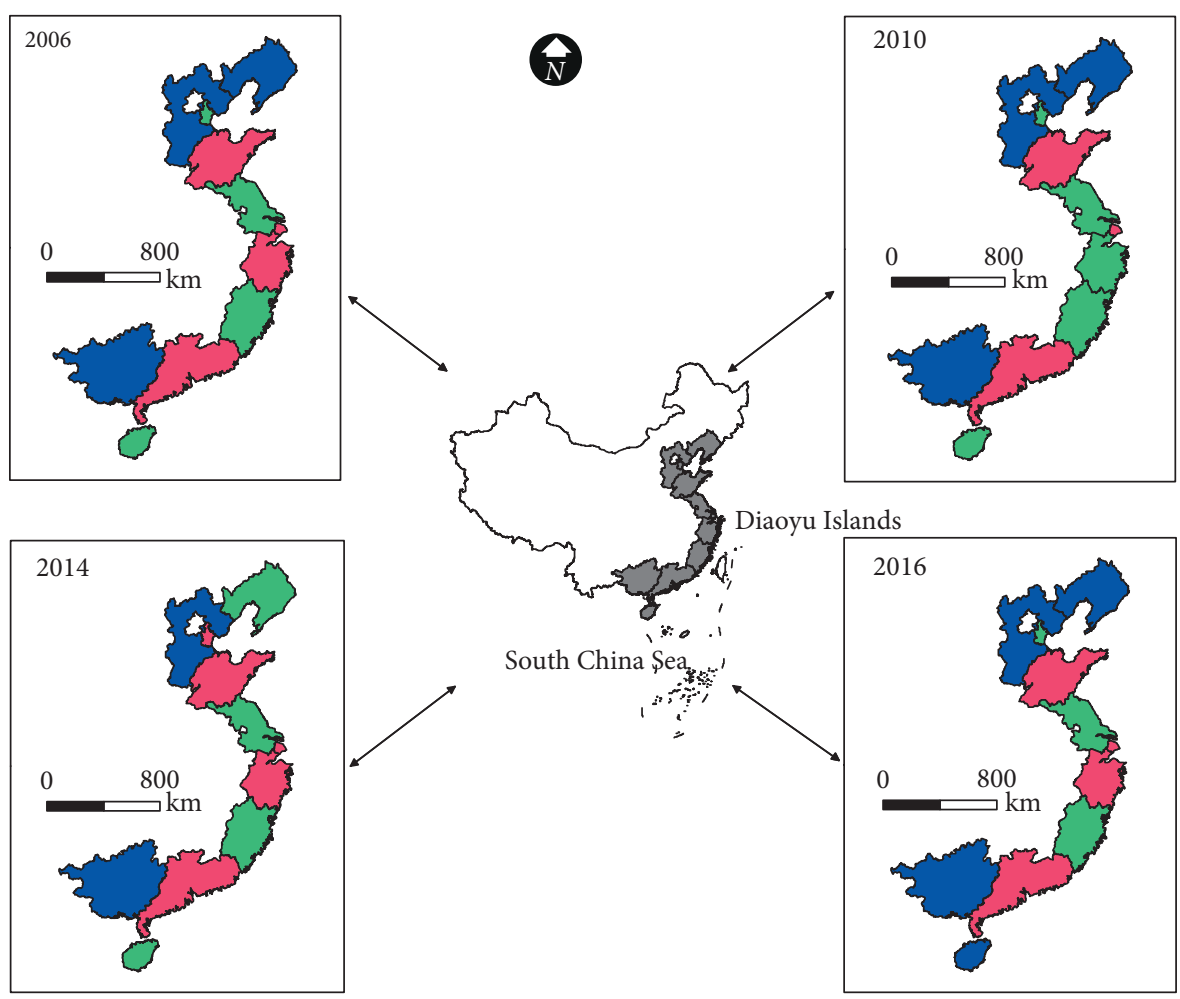

Primary stage

Intermediate stage

Advanced stage

(a)

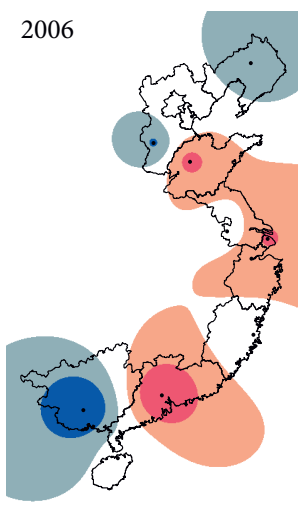

2010

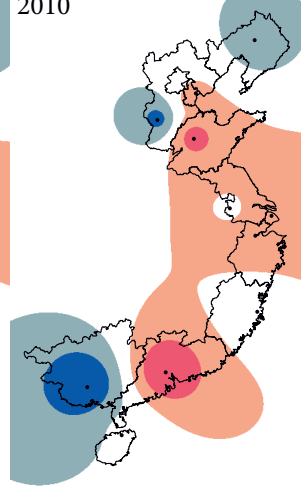

$\square$ 0.0097-0.1680

$\square 0.1681-0.2381$

$\square 0.2382-0.3082$

$\square 0.3083-0.3783$

$\square 0.3784-0.4486$
$\square$ 0.1211-0.1991
$\square \quad 0.1992-0.2271$
$\square 0.2772-0.3551$
$\square \quad 0.3552-0.4331$
$\square 0.4332-0.5112$

2014

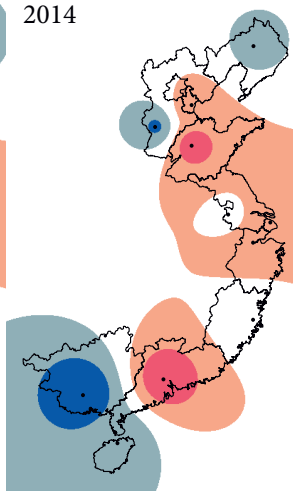

$\square \quad 0.1528-0.236$

$\square 0.2362-0.3193$

$\square$ 0.3194-0.4026

$\square$ 0.4027-0.4859

0.4860-0.5692

(b)

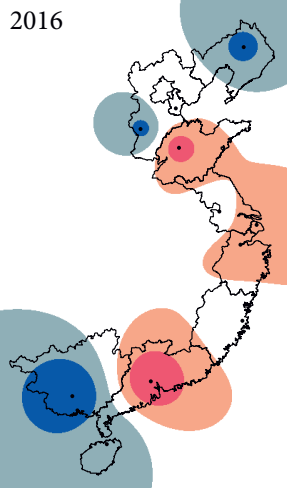

$\square$ 0.1680-0.2577

$0.2578-0.3475$

$\square$ 0.3476-0.4372

$\square$ 0.4372-0.5269

$\square 0.5270-0.6168$

FIGURE 4: Spatial features of the high-quality development of China's marine economy.

gathering of talents in marine science and technology, and superior geographical location and rich marine resources. Shanghai has, historically, always been in a unique position in China's marine economy.
(3) As a large coastal province in Eastern China, Shandong Province has achieved high added values from several industries, such as marine fishery and marine transportation, which were at the forefront of the country. After the proposal of developing a "Blue 
Economic Zone" (BEZ) on the Shandong Peninsula, a plan was quickly initiated. The development of the marine economy in Shandong started relatively late, but its scale has been increasing steadily. It is likely that Shandong may catch up and take a leading position in the marine economy with Guangdong Province.

(4) In 2011, the State Council approved the demonstration zone for marine economic development in Zhejiang Province. Since then, the marine economy has started to play an increasingly important role in Zhejiang's national economic development. In 2015, the national port integration initiative was proposed, and the Ningbo Port and Zhoushan Port in Zhejiang were integrated in 2016. Following the port integration, the pace of high-quality development of Zhejiang's marine economy has been accelerating.

(5) Tianjin Province is a typical coastal city in the BER region, and marine exploitation, planning, and development are key to its development. Its geographical advantages provide a good basis for the development of the marine economy: the province has supportive polices, and its advantages in science and technology enable it to promote the transformation of the marine economy. In addition, the "Tianjin model" has offered other coastal cities in the BER region a valuable reference for the development of the marine economy.

3.5. Intermediate-Level Areas. Tier II areas are intermediatelevel areas, including Fujian, Jiangsu, Hainan, and Liaoning. The following describes each area in relation to sustainable growth in the marine economy:

(1) Fujian Province has obvious advantages in five major marine industries: marine fishery, marine transportation, marine tourism, marine engineering, and marine ships. However, the improvement of its marine economic competitiveness has been restricted in the short term as it has insufficient time and space to resolve excess capacity issues, upgrade and optimize industrial structures, and achieve innovation-driven development.

(2) Jiangsu Province has rich marine resources, a good material basis for the development of the marine economy. In addition, it has achieved remarkable progress in its marine technological innovation and transformation. However, the development of the marine economy in Jiangsu has resulted in minor issues, a low level of development, and great ecological pressure. Considering the proportion of the ocean in some of the strong marine provinces, the scale of Jiangsu's marine economy is relatively small to the overall promotion of the high-quality development of the marine economy in the province.

(3) The Xisha, Nansha, and Zhongsha islands of Hainan Province are actually traditional military control areas and the front line of coastal defense. Except for coastal tourism, other marine industries in Hainan need to be improved (as the research data were only up to 2016, there is a certain time lag in the effectiveness of the promotion of the Hainan pilot freetrade zone, which was excluded from this study).

(4) Since the proposal for the construction of "Liaoning at sea" and the continuous growth of the development and exploitation of the ocean, the landforms along the coast of Liaoning continue to be destroyed, increasing the pressure on the marine ecological environment. It is an important challenge for Liaoning to scientifically adjust the layout of the marine industry in the coastal areas of the province and change the pattern of marine economic development in a timely manner in order to achieve the high-quality development of the marine economy.

3.6. Primary-Level Areas. Tier III areas are primary-level areas, which include Hebei and Guangxi. The following describes each area in relation to sustainable growth in the marine economy:

(1) $90 \%$ of ocean-related enterprises in Hebei Province are located in Qin-Tang-Cang zones. As the sea has been separated from the land for a long time, the integration of land and sea has not been considered in Hebei. Moreover, it provides low economic benefits from the comprehensive utilization of marine resources, so the overall strength of Hebei's marine economy is relatively inferior in the BER region.

(2) Guangxi is a coastal area that only developed recently and has been facing issues expected of a small marine economy, such as weak maritime industrial structures and many challenges in economic transformation. Thus, it has a weak material basis for contributing to the high-quality development of China's marine economy.

\section{Discussions}

With the growing understanding of the concept of sustainable development, it has been a consensus among coastal countries around the world to develop the marine economy in the context of globalization and a shared future $[4,5]$. From a perspective of sustainability, seeking external environmental strategies and internal dynamic mechanisms to optimize the development model of the marine economy will be the key areas of science research and the development of the marine economy $[6,9]$. As policies on the development and utilization of sea areas have gradually changed, the operation mode and structural characteristics of micromarine economies have begun to change as well (Figure 5). Coastal areas are typical areas of rapid urbanization and development of the marine economy. This study has taken the coastal areas in China as spatial samples to study the high-quality development of the marine economy and met current political requirements and practical needs. The 


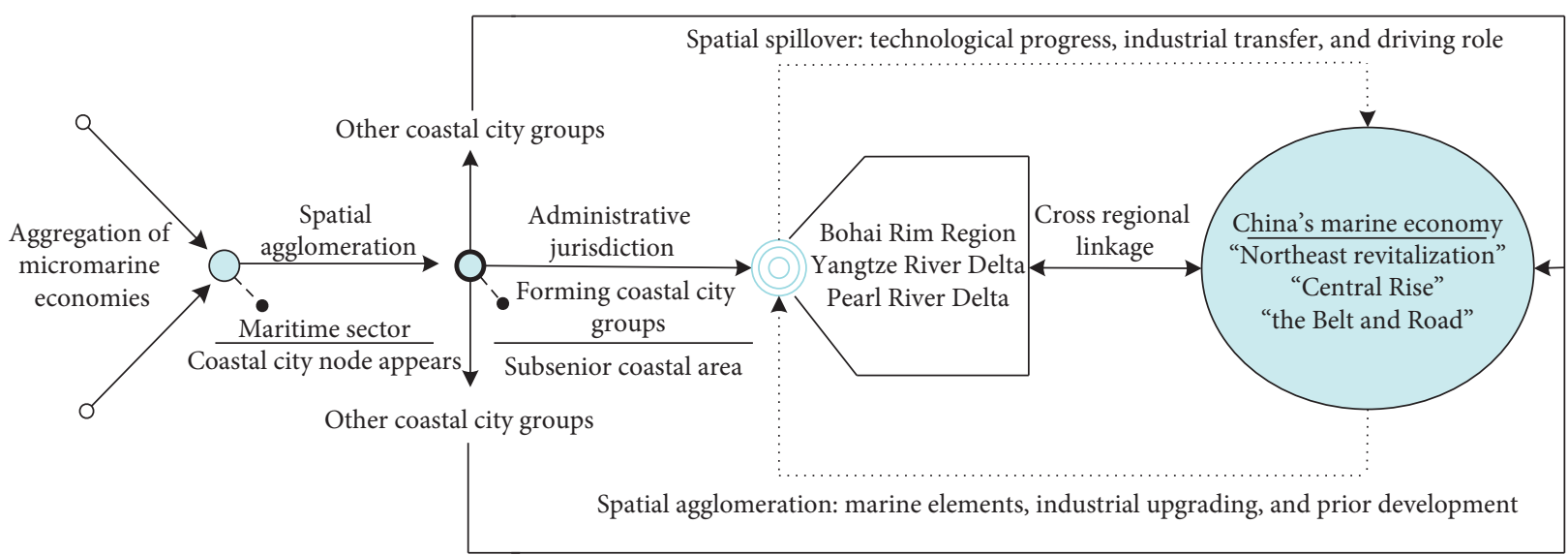

FIGURE 5: Spatial features of the high-quality development of China's marine economy.

discussion on the pattern of the high-quality development of marine economy can provide a reference to other coastal countries in the world.

The pattern of the high-quality development of the marine economy is a key issue that needs to be considered for the development of coastal areas; it poses as an important path for coastal countries to actively explore to help them achieve sustainable growth. The global economy is undergoing a cyclical slowdown. Therefore, the risks of sudden, unusual, and irregular fluctuations continue to intensify the uncertainty of economic development, meaning that traditional theories of economic growth would not be applicable to the sustainable growth of the marine economy. Thanks to the promotion of several international science programs, the establishment of sustainable science has laid the theoretical foundation for solving marine-related problems [32]. It has gradually become the core objective of marine economic development to transform, shifting from the quantity of sustainable growth to the quality of sustainable growth, and seek growth that has low consumption, less pollution, and high output.

From the perspective of sustainable development, the theoretical framework and evaluation system of the highquality development of the marine economy have not yet been established, and empirical analysis in this area still needs to be improved. The study has combined analysis of typical cases, and we study the pattern of high-quality development using coastal areas in China as examples, increasing the reliability of research results. The case study of this paper is different from the case analysis of the optimal economic management of the local coastal zone in a single area $[22,23]$ or the qualitative division of stages of marine economic development. The study has adopted a combination of the index method and the threshold model to quantitatively compare the marine economy in various coastal areas regarding their stage of high-quality development, state of operation, and spatial-temporal evolution of development. This method can accurately identify the development orientation of the marine economy in coastal cities. In addition, it is different from the economic highquality development model [33]. This research intends to propose solutions to resolve the bottlenecks of marine economic development and marine ecological environment in the coastal areas, and we attempt to construct models for sustainable development in terms of ecological benefit and economic benefits.

The study is significant in alleviating the pressure of high-density agglomeration, high-intensity development, high-level pollution, and high-risk ecological environment due to the rapid growth of the marine economy in coastal cities. It also seeks the "economic-ecological" interactioncoupling model of sustainable development [34].

The limitations of this study are as follows. Based on the availability and representativeness of the national oceanographic data, the research team only collected, screened, and processed relevant data in the period between 2006 and 2016 and then quantitatively analyzed the state of the high-quality development of the marine economy in China's coastal areas. Coastal agglomerated areas were mainly taken as core research objects, and the development of the upstream and downstream industrial chains related to marine industries inland was not considered, which may have had a certain impact on the research results.

\section{Conclusions}

This study has systematically analyzed the features of the cross-scale transfer of the high-quality development of the marine economy, has constructed a model for the evolution of development in time and space, and has integrated multiple agents, elements, and systems. China's coastal areas in the period between 2006 and 2016 were taken as spatial samples to assess its spatial-temporal evolution and give type classifications. The results of the research have found that

(1) The high-quality development of China's marine economy shows remarkable policy-oriented characteristics. The issue of coastal policies has evolved over time from a brief and scattered pattern to a systematic and intensive pattern, while the focus of the policies has shifted from the growth rate to the quality of marine economic development. 
(2) In terms of time evolution, differences in the highquality development of China's marine economy increased with time, but the high-quality development steadily improved and showed club convergence, indicating a development process from the primary stage to the fluctuation stage to the stable stage. In terms of spatial evolution, the coastal areas of the YRD from 2006 to 2016 continued to be the hot spots, in general. The coastal areas of the PRD and the BER showed a mix of hot and cold spots. The spatial evolution pattern of high-quality development of the marine economy basically formed a multipolar distribution, alternating between high, medium, and low qualities. The pattern of development presents the characteristics of regional spatial linkage rather than a monolithic development.

(3) Classification of high-quality development of marine economy. Based on the score ranges, advanced-level areas include Guangdong, Shanghai, Shandong, Zhejiang, and Tianjin; intermediate-level areas include Fujian, Jiangsu, Hainan, and Liaoning; and primary-level areas include Hebei and Guangxi.

From a perspective of sustainable development, research on the high-quality development of the marine economy needs to address scientific issues, such as high-level integration and interdisciplinary research, unification of conceptual framework and establishment of theoretical systems, determination of evaluation scales and thresholds, and improvement of marine economic statistical systems in the future.

\section{Data Availability}

The data used in this paper are given in the government statistical yearbook.

\section{Conflicts of Interest}

The authors have no conflicts of interest.

\section{Acknowledgments}

This work was supported by the general program of the National Natural Science Foundation of China (41976207).

\section{References}

[1] R. E. Smalley, Our Energy Challenge, Columbia University, New York City, NY, USA, 2003.

[2] J. Yang, W. Liu, Y. H. Li, X. M. Li, and Q. S. Ge, "Simulating intraurban land use dynamics under multiple scenarios based on fuzzy cellular automata: a case study of jinzhou district, dalian," Complexity, vol. 2018, Article ID 7202985, 17 pages, 2018.

[3] J. Yang, P. Xie, J. C. Xi, Q. S. Ge, X. M. Li, and Z. D. Ma, "LUCC simulation based on the cellular automata simulation: a case study of dalian economic and techological development zone," Acta Geographica Sinica, vol. 70, no. 3, pp. 461-475, 2015 .
[4] E. Ostrom, "A general framework for analyzing sustainability of social-ecological systems," Science, vol. 325, no. 5939, pp. 419-422, 2009.

[5] M. Xie, J. Wang, and K. Chen, "Coordinated development analysis of the "resources-environment-ecology-economysociety" complex system in China," Sustainability, vol. 8, no. 6, pp. 582-604, 2016.

[6] K. Pakalniete, J. Aigars, M. Czajkowski, S. Strake, E. Zawojska, and N. Hanley, "Understanding the distribution of economic benefits from improving coastal and marine ecosystems," Science of the Total Environment, vol. 584-585, pp. 29-40, 2017.

[7] J.-B. Marre, T. Olivier, S. Pascoe, S. Jennings, J. Boncoeur, and L. Coglan, "Is economic valuation of ecosystem services useful to decision-makers? lessons learned from Australian coastal and marine management," Journal of Environmental Management, vol. 178, pp. 52-62, 2016.

[8] K. Chakraborty, K. Das, and T. K. Kar, "Modeling and analysis of a marine plankton system with nutrient recycling and diffusion," Complexity, vol. 21, no. 1, pp. 229-241, 2014.

[9] D. Ferrol-Schulte, M. Wolff, S. Ferse, and M. Glaser, "Sustainable livelihoods approach in tropical coastal and marine social-ecological systems: a review," Marine Policy, vol. 42, no. 14, pp. 253-258, 2013.

[10] K. Inaba, "Japanese marine biological stations: preface to the special issue," Regional Studies in Marine Science, vol. 2, pp. 154-157, 2015.

[11] G. Nilsen, "Surplus production and marine resource use in the north norwegian iron age," International Journal of Nautical Archaeology, vol. 46, no. 2, pp. 231-252, 2017.

[12] M. White and G. O'Sullivan, "Implications of EUROGOOS on marine policy making in a small maritime economy," Elsevier Oceanography Series, vol. 62, pp. 278-285, 1997.

[13] S. E. Schutz and A.-M. Slater, "From strategic marine planning to project licences-striking a balance between predictability and adaptability in the management of aquaculture and offshore wind farms," Marine Policy, vol. 110, Article ID 103556, 2019.

[14] B. Li, Z. Y. Shi, Z. L. Han, and C. Tian, "Spatio-temporal difference and influencing factors of environmental adaptability measurement of human-sea economic system in Bohai Rim region," Acta Geographica Sinica, vol. 73, no. 6, pp. 1121-1132, 2018.

[15] R. A. M. Lauerburg, R. Diekmann, B. Blanz et al., "Socioecological vulnerability to tipping points: a review of empirical approaches and their use for marine management," Science of the Total Environment, vol. 705, Article ID 135838, 2020.

[16] T. Agardy, M. Cody, S. Hastings et al., "Looking beyond the horizon: an early warning system to keep marine mammal information relevant for conservation," Aquatic Conservation: Marine and Freshwater Ecosystems, vol. 29, no. S2, pp. 71-83, 2019.

[17] L. H. Gao and Q. Gao, "Validation and calculation of the coordination degree of interactive relationships in the marine eco-economic system," Resources Science, vol. 34, no. 1, pp. 173-184, 2012.

[18] D. Jia, "Coupling and coordination of marine high-end human resources and marine innovative economic development ability," Journal of Coastal Research, vol. 94, no. sp1, pp. 573-576, 2019.

[19] S.-H. Wang, Y.-C. Wang, and M.-L. Song, "Construction and analogue simulation of TERE model for measuring marine bearing capacity in Qingdao," Journal of Cleaner Production, vol. 167, pp. 1303-1313, 2017. 
[20] Y. Zhang and A. Kendall, "Consequential analysis of algal biofuels: benefits to ocean resources," Journal of Cleaner Production, vol. 231, pp. 35-42, 2019.

[21] J. J. Freer, G. A. Tarling, M. A. Collins, J. C. Partridge, and M. J. Genner, "Predicting future distributions of lanternfish, a significant ecological resource within the Southern Ocean," Diversity and Distributions, vol. 25, no. 8, pp. 1259-1272, 2019.

[22] B. Li, C. Tian, and Z. Y. Shi, "Spatio-temporal analysis and type classification of marine economic growth quality in Bohai Rim region," Resources Science, vol. 39, no. 11, pp. 2052-2061, 2017.

[23] B. Li, C. Tian, Z. Y. Shi, and Z. L. Han, "Spatial characteristics and influencing factors of marine economic growth quality in Liaoning coastal areas," Progress in Geography, vol. 38, no. 7, pp. 1080-1092, 2019.

[24] K.-H. Lee, J. S. Noh, and J. S. Khim, "The blue economy and the united nations' sustainable development goals: challenges and opportunities," Environment International, vol. 137, Article ID 105528, 2020.

[25] M. D. Smith, J. Lynham, J. N. Sanchirico, and J. A. Wilson, "Political economy of marine reserves: understanding the role of opportunity costs," Proceedings of the National Academy of Sciences, vol. 107, no. 43, pp. 18300-18305, 2010.

[26] M. W. Lin, C. Huang, and Z. S. Xu, "TOPSIS method based on correlation coefficient and entropy measure for linguistic pythagorean fuzzy sets and its application to multiple attribute decision making," Complexity, vol. 2019, Article ID 6967390, 16 pages, 2019.

[27] M.-S. Yang and Z. Hussain, "Fuzzy entropy for pythagorean fuzzy sets with application to multicriterion decision making," Complexity, vol. 2018, Article ID 2832839, 14 pages, 2018.

[28] S. H. Jin, J. Yang, E. X. Wang, and J. Liu, "The influence of high-speed rail on ice-snow tourism in northeastern China," Tourism Management, vol. 78, Article ID 104070, 2020.

[29] R. Ding, "The complex network theory-based urban land-use and transport interaction studies," Complexity, vol. 2019, Article ID 4180890, 14 pages, 2019.

[30] B. W. Silverman, Density Estimation for Statistics and Data Analysis, CRC Press, Boca Raton, FL, USA, 1986.

[31] S. Wallenstein, C. L. Zucker, and J. L. Fleiss, "Some statistical methods useful in circulation research," Circulation Research, vol. 47, no. 1, pp. 1-9, 1980.

[32] R. W. Kates, W. C. Clark, R. Corell et al., "Sustainability Science," Science, vol. 292, no. 5517, pp. 641-642, 2001.

[33] Q. B. Di, Z. Yu, and L. X. Xu, "Spatial-temporal coordination mode of marine economic development under the background of high quality growth: based on the empirical study of prefecture-level cities in Circum-Bohai Sea," Scientia Geographica Sinica, vol. 39, no. 10, pp. 1621-1630, 2019.

[34] F. Y. Guo, L. J. Tong, Z. G. Liu, H. J. Zhao, and A. L. Hou, "Spatial-temporal pattern and influencing factors of industrial ecology in Shandong province: based on panel data of 17 cities," Geographical Research, vol. 38, no. 9, pp. 2226-2238, 2019. 